\title{
Liposome Preparation of Tekelan Leaf (Chromolaenaodorata L.) Extract: Manufacturing and Evaluation
}

\author{
S Rahmi' , Rosidah ${ }^{1, *}$, T Widyawati ${ }^{2}$, Sumaiyah ${ }^{3}$
}

S Rahmi1, Rosidah ${ }^{1, *}$, T Widyawati $^{2}$, Sumaiyah $^{3}$

'Department of Pharmacology, Faculty of Pharmacy, Universitas Sumatera Utara, INDONESIA.

${ }^{2}$ Department of Pharmacology, Faculty of Medicine, Universitas Sumatera Utara INDONESIA.

${ }^{3}$ Department of Pharmaceutical Technology, Faculty of Pharmacy, Universitas Sumatera Utara, INDONESIA.

\section{Correspondence}

\section{Rosidah}

Department of Pharmacology, Faculty of Pharmacy, Universitas Sumatera Utara, INDONESIA

E-mail: Rosidah@usu.ac.id

History

- Submission Date: 17-10-2021;

- Review completed: 29-10-2021;

- Accepted Date: 15-11-2021.

DOI : 10.5530/pj.2022.14.8

Article Available online

http://www.phcogj.com/v14/i1

\section{Copyright}

(C) 2022 Phcogi.Com. This is an openaccess article distributed under the terms of the Creative Commons Attribution 4.0 International license.

\begin{abstract}
Background: Liposomes are biocompatible, biodegradable, and non-immunogenic due to their phospholipid composition which is similar to cell membranes. Active chemicals that are contained in liposomes preparation has a goal in improving solubility, minimizing adverse effects, extending release, protecting drugs, targeting drugs, and increasing efficacy. Objective: The purpose of this study was to formulate the ethanol extract of tekelan leaves into liposome preparations and to determine differences in particle size, polydispersity index (PI) and stability. Materials and Methods: This research begins with making extract by maceration. The extract formed was then formulated into liposome preparations with the composition of F1 ( $30 \mathrm{mmol}), \mathrm{F} 2(40 \mathrm{mmol})$ and F3 $(50 \mathrm{mmol})$ ingredients. The formulation was carried out by thin layer hydration with variations in sonication time of 10 minutes, 20 minutes and 30 minutes. Evaluation of liposomes was carried out organoleptically, testing $\mathrm{pH}$, particle size, polydispersity index (PI), and physical stability at room temperature. Data analysis was carried out statistically using SPSS 20.0 One Way ANOVA method to see if there were differences in each group. The average $\mathrm{pH}$ test results of the three formulations were $6.2 \pm 0.3$. The particle size results in the 30th minutes obtained particle sizes of F1 $(293.63 \pm 1.6 \mathrm{~nm}), \mathrm{F} 2(201.9 \pm 1.5 \mathrm{~nm})$ and F3 $(143.17 \pm 0.6 \mathrm{~nm})$. Results: The results of the polydispersion index (PI) were F1 $(0.307 \pm 0.03), F 2(0.275 \pm 0.06)$ and F3 $(0.229 \pm 0.02)$. The results of the observation of room temperature stability obtained that the organoleptic results formed two layers, namely a clear layer and a cloudy layer. In the One-Way ANOVA test, a significance value of $p>0.05(0.068)$ was obtained Conclusion: Liposomes produced from ethanol extract of tekelan leaves are stable when stored at low temperatures $\left(4 \pm 0.5^{\circ} \mathrm{C}\right)$ with an organoleptic state of odorless, dark green color and thick consistency. Key words: Liposomes, Tekelan, pH, Stability, Particle size.
\end{abstract}

\section{INTRODUCTION}

Tekelan (Chromolaena odorata L.) is an Asteraceae plant that contains active substances such as alkaloids, flavonoids (auron, chalcone, flavones, and flavonols), saponins, tannins, high amino acid content, and other phenolic content in the form of extracts. ${ }^{1}$ Previous research has extracted and discovered flavonol compounds containing quercetin (3'-4'-dihydroxyflavones) in tekelan leaves. ${ }^{2}$ Quercetin in a tekelan leaf ethanol extract is classed as Biopharmaceutical Classification System (BSC) II due to its limited water solubility and high permeability. ${ }^{3}$ Because of the low solubility and permeability of quercetin, a formulation that can increase its bioavailability is needed to achieve the desired therapeutic effect. The drug delivery system refers to a group of medicine delivery systems that are intended to improve therapeutic effect through controlled release. In addition to improving bioavailability and therapeutic impact, it is used for targeted pharmaceutical release. ${ }^{4}$

Liposomes are one of the drug delivery techniques that is currently being developed. Liposomes are an excellent carrier for increasing the solubility and penetration of the chemicals they transport. Liposomes have both hydrophilic and lipophilic structures, which trap hydrophilic medications in the water core and lipophilic drugs in the lipid bilayer. ${ }^{5}$ Along with their good solubilizing power, their manufacture is easier and makes liposomes an attractive drug carrier system. ${ }^{6}$ Liposomes are biocompatible, biodegradable, and non-immunogenic due to their phospholipid composition (which is similar to cell membranes) Pharmaceuticals (active chemicals) are contained in liposomes with the goal of improving solubility, minimizing adverse effects, extending release, protecting drugs, targeting drugs, and increasing efficacy. ${ }^{7}$ The researcher is interested in employing the thin layer hydration approach to formulate the ethanol extract of tekelan leaves into liposome dosage forms with the goal of enhancing the bioavailability and therapeutic impact of the ethanolic extract of tekelan leaves.

\section{MATERIALS AND METHODS}

\section{Materials}

The materials used in this study were tekelan leaves, 96\% ethanol, distilled water (Ikapharmindo), Lipoid S75, Lipoid DMPG-Na, Span-60, Cholesterol (Sigma Aldrich), methanol (Merck), chloroform (Merck) and PBS (Phosphate). Saline Buffers) (Merck).

\section{Preparation of Tekelan leaves}

Fresh tekelan leaves are washed, then separated from the branches, and dried in a drying cabinet at a temperature of $30-40 \mathrm{oC}$ for 5 days or until the leaves are dry enough. The dried leaves are then ground into powder. ${ }^{8}$

\section{Extraction of Tekelan leaves}

A total of $2000 \mathrm{~g}$ of Tekelan leaf powder was extracted using 96 percent ethanol as the solvent. The maceration procedure employed up to 15000

Cite this article: Rahmi S, Rosidah, Widyawati T, Sumaiyah. Liposome Preparation of Tekelan Leaf (Chromolaenaodorata L.) Extract: Manufacturing and Evaluation. Pharmacogn J. 2022;14(1): 56-62. 
$\mathrm{ml}$ of 96 percent ethanol. The maceration procedure was carried out by placing 7.5 parts of the liquid into a vessel containing 10 parts of simplicia with an appropriate degree of fineness, then covering and leaving for 5 days, protected from light, stirring regularly. The pulp is pressed with a flannel cloth and then filtered using filter paper after 5 days of screening. The dregs were rinsed with the remaining 96 percent $5000 \mathrm{ml}$ ethanol solvent before being filtered again. The filtrate obtained was concentrated with a rotary evaporator at a temperature of $50^{\circ} \mathrm{C}$ until a thick extract were obtained. ${ }^{8}$

\section{Preparation liposomes by thin layer hydration method}

The composition of the liposome formulation of tekelan leaf ethanol extract was $50 \mathrm{mmol}$. The preparations are divided into two mixtures in the formulation. A mixture (consisting of lipoid S75, lipoid DMPG$\mathrm{Na}$, cholesterol and span 60). B Mixture (consisting of methanol, chloroform, ethanol extract of tekelan leaves). Each material's specific gravity is used to compute its density. The entire amount of substance is $50 \mathrm{mmol}$. The extract was dissolved in methanol and chloroform in a concentration of $100 \mathrm{mg}$ (5:5) after being dissolved and homogenized in mixture. A rotary evaporator was used to evaporate the contents of a round tool flask, then heated to a temperature of $60^{\circ} \mathrm{C}$ at a pressure of $200 \mathrm{mBar}$ for 1 hour, repeated it until a thin film formed on the round bottom flask's walls, then added PBS to the flask. Extracted Liposomes were purified using a PD 10 column, placed in a container, and shrunk using ultrasonic with a 30 minute sonication duration. ${ }^{9}$

\section{Liposome particle size observations}

The purified liposomes were analyzed by Particle Size Analyzer (PSA). Note the change in particle size. The formulation of liposomes can be seen in Table 1 .

\section{Characteristics of liposomes}

Determination of Characteristics of Liposomes was conducted by determine the color and odor of liposomes by visually, Then continue to Measuring pHusing a $\mathrm{pH}$ meter at a temperature of $25^{\circ} \mathrm{C} \pm 2$ by replication of three times. ${ }^{9,10}$ Measurement of particle size and zeta potential was carried out using a particle size analyzer (Horiba SZ 100), the sample was put into a cuvette after $100 \mathrm{x}$ dilution. The stability of the liposome preparation was evaluated organoleptically in the form of color changes and the formation of particulates dispersed into the PBS carrier liquid. ${ }^{11}$

\section{Storage stability at room temperature $\left(25 \pm 0.5^{\circ} \mathrm{C}\right)$}

The preparations were stored at room temperature $\left(25 \pm 0.5^{\circ} \mathrm{C}\right)$ for 12 weeks, then observed for 12 weeks. Observations were made in the form of organoleptic observations (change in color, odor, phase separation and clarity). In addition, particle measurements of each formulation were carried out. ${ }^{12}$

\section{Liposomal morphology test}

Liposomal morphology was carried out using TEM (Transmission Electron Microscopy) and PSA (Particle Size Analyzer) tools. In addition, stability and percent adsorption efficiency tests (\% EE) were carried out.

\section{TEM (Transmission Electron Microscopy)}

TEM was conducted at the Chemistry Laboratory, Gadjah Mada University. TEM was performed to analyze the inner morphology of liposome particles, crystal structure and specimen composition. The liposome sample of tekelan leaf extract was diluted with dilutions of 20x and 50x, and then the sample was dripped onto the formvar coated cumprum grid as much as one drop and dried at room temperature. After drying, it was analyzed by TEM. The sample was put into a container and analyzed at a temperature of $25^{\circ} \mathrm{C} .{ }^{11}$

\section{Determination of percent adsorption efficiency}

A total of $1 \mathrm{~mL}$ of liposome suspension was dissolved in phosphate buffer saline $\mathrm{pH} 6.0$ in a ratio of 1:10. The aqueous suspension was centrifuged at $3000 \mathrm{rpm}$ for $30 \mathrm{~min}$. The supernatant obtained was pipette $1.0 \mathrm{~mL}$ and put into a $10 \mathrm{~mL}$ volumetric flask, then the volume was filled with saline phosphate buffer $\mathrm{pH} 6.0$ to the limit line. Then 1.0 $\mathrm{mL}$ pipette was added and 6.0 saline phosphate buffer was added in a $10 \mathrm{~mL}$ volumetric flask, then filtered with filter paper. The absorbance of the solution was measured at a wavelength of $368 \mathrm{~nm}$.

The efficiency of vesicle entrapment was determined by separating the free drug from the drug absorbing vesicle using the ultracentrifugation technique. The liposome suspension was centrifuged for 30 minutes at $3000 \mathrm{rpm}$ and a temperature of $4^{\circ} \mathrm{C}$ in order to separate the nonadsorbed drug. The amount of drug (FD) was determined on the supernatant. The concentration of the centrifuged supernatant was determined using UV-VIS spectrophotometry. ${ }^{13}$

The adsorption efficiency of $9 \% \mathrm{EE}$ ) is calculated by the formula:

$\% \mathrm{EE} \quad=\frac{T D-F D}{T D} \times 100 \%$

Information:

$\mathrm{TD}=$ Total compounds contained in the formula

$\mathrm{FD}=$ The number of compounds detected in the supernatant

Data analysis

Determination of the size and distribution of liposomes was observed with PSA (Particle Size Analyzer) to determine the size of liposomes and particle distribution or polydispersity index (PI). TEM (Transmission Electron Microscopy) to analyze the inside morphology of liposome particles, crystal structure and specimen composition. Stability test to see the stability of liposome preparations in storage. The data obtained were then analyzed descriptively and presented in the form of tables and figures.

Table 1: Tekelan leaf ethanol extract liposome formulation (C. odorata L.).

\begin{tabular}{lccc} 
Ingredients & F1 (30 mmol) & F2 (40 mmol) & F3 (50 mmol) \\
\hline Tekelan leaf ethanol extract & $100 \mathrm{mg}$ & $100 \mathrm{mg}$ & $100 \mathrm{mg}$ \\
Chloroform & $5 \mathrm{~mL}$ & $5 \mathrm{~mL}$ & $5 \mathrm{~mL}$ \\
Methanol & $5 \mathrm{~mL}$ & $5 \mathrm{~mL}$ & $5 \mathrm{~mL}$ \\
Lipoid S75 & $258.97 \mathrm{mg}$ & $345.33 \mathrm{mg}$ & $431.68 \mathrm{mg}$ \\
Lipoid DMPG-Na & $6.815 \mathrm{mg}$ & $9.09 \mathrm{mg}$ & $11.36 \mathrm{mg}$ \\
Cholesterol & $5.8 \mathrm{mg}$ & $7.74 \mathrm{mg}$ & $9.67 \mathrm{mg}$ \\
Span-60 & $1.83 \mathrm{mg}$ & $2.44 \mathrm{mg}$ & $3.05 \mathrm{mg}$ \\
PBS & $10 \mathrm{~mL}$ & $10 \mathrm{~mL}$ & $10 \mathrm{~mL}$
\end{tabular}




\section{RESULTS AND DISCUSSION}

\section{Result of dried sample characteristic examination}

The results of dried sample characterisation are used to determine the Dried Sample's specifications. Because the origin of the growing environment impacts the content of the active component, this specification is used to determine the clarity of the material under investigation. The water content, total ash content, acid insoluble ash content, water soluble extract content, and ethanol soluble extract content of Tekelan leaves were all determined. Table 2 shows the findings of the investigation of these parameters.

The water content of tekelan leaf dried powder was 6.62 percent, which was less than the Ministry of Health of The Republic of Indonesia's requirement of less than $10 \%$. The water content test is used to determine the maximum amount of water that can be present in the material. The amount of water in traditional medicines is related to microbial development and accelerates the hydrolysis of chemical ingredients, resulting in a reduction in their quality. ${ }^{14}$ The amount of chemicals that could be extracted with water from a dried samples was determined by determining the amounts of water soluble extract. The amount of water soluble extract in tekelan leaves was 21.11 percent, which met the Ministry of Health of the Republic of Indonesia's standard of not less than $5 \%$. The number of chemicals that could be extracted with ethanol from a dried samples was determined by determining the ethanol soluble extract content. The ethanol soluble extract level at the tackle was $16.89 \%$, which met the Ministry of Health of the Republic of Indonesia's guideline of not less than 3.5 percent. $^{14}$

The ash content of a product is determined to assess how much nonvolatile material remains. Ash can arise from the plant tissue itself or additional impurities like sand or dirt when the total ash concentration is high. The acid insoluble ash content test is used to detect how much impurity is present in sand or silicate soil. ${ }^{14}$ The total ash content obtained was 7.92 percent, which met the standards of the Ministry of Health of the Republic of Indonesia, which were not to exceed 13 percent. Despite the fact that the acid insoluble ash content obtained was 1.2 percent, it did not fulfill the Ministry of Health of the Republic of Indonesia's standards of not more than $1 \%$.

\section{Results of identification of chemical compounds in} Tekelan leaves

Identification of chemical compounds in tekelan leaves aims to prove the presence or absence of compounds such as alkaloids, flavonoids, tannins, steroids and saponins. The identification results can be seen in Table 3 below.

\section{Liposomal pH measurement results}

Measurement of $\mathrm{pH}$ is carried out to find out what the $\mathrm{pH}$ of the preparation is because $\mathrm{pH}$ can affect the availability of drugs in molecular form. Drugs in molecular form can penetrate easily. The results of the measurement of the $\mathrm{pH}$ of the liposomes were seen before and after being purified. These results can be seen in Table 4 .

Table 2: Results of examination of the characteristics of dried tekelan leaves ( $C$. odorata $\mathrm{L}$.).

\begin{tabular}{lll}
\hline No & Parameter & Results \\
\hline 1 & water content & $6.62 \%$ \\
2 & water soluble essence & $21.11 \%$ \\
3 & Ethanol soluble extract content & $16.89 \%$ \\
4 & total ash content & $7.92 \%$ \\
5 & acid insoluble ash content & $1.2 \%$
\end{tabular}

Table 3: Identification results of chemical compounds of tekelan leaves.

\begin{tabular}{lcc} 
Compound & Powder & Extract \\
\hline Alkaloids & + & + \\
Flavonoids & + & + \\
Tanins & + & + \\
Saponins & + & + \\
Steroids/Triterpenoids & + & + \\
Glycoside & + & +
\end{tabular}

Table 4: Results of measurement of liposomal pH ethanol extract of tekelan Leaves (C. odorata L.).

\begin{tabular}{cccc} 
Formula & Replication & $\mathrm{pH}$ & Average \pm SD \\
\hline \multirow{2}{*}{ I } & 1 & 6.2 & \\
& 2 & 6.1 & $6.1 \pm 0.1$ \\
& 3 & 6.0 & \\
II & 1 & 6.1 & \\
& 2 & 6.2 & $6.2 \pm 0.6$ \\
& 3 & 6.2 & \\
III & 1 & 6.3 & $6.2 \pm 0.1$ \\
& 2 & 6.1 & \\
& 3 & 6.2 & \\
\end{tabular}

The liposome formulation of the ethanol extract of tekelan leaves has a $\mathrm{pH}$ close to neutral, according to the $\mathrm{pH}$ measurements. It's important that the $\mathrm{pH}$ level isn't overly acidic or basic. Because the $\mathrm{pH}$ level must be adjusted to match the $\mathrm{pH}$ of the body's fluids. An acidosis phase will occur if the body fluids become overly acidic due to the use of liposomes with an acidic $\mathrm{pH}$, with symptoms such as an increase in heart rate, a characteristic sour-smelling breath that shows the presence of ketoacidosis, decreased hunger, and others. However, if the $\mathrm{pH}$ is too alkaline, the body's potassium mineral balance and blood calcium levels would be disrupted. Alkalosis is the medical term for this illness. ${ }^{15}$

\section{Observation of particle size and zeta potential}

The results of the measurement of liposome particles from the ethanol extract of tekelan leaves using the PSA (Particle Size Analyzer) tool. The results of the particle size readings can be seen in Table 5 .

Table 5 reveals that the smallest particle size and polydispersity index of niosomes at 30 minutes at F3 $(50 \mathrm{mmol})$ is $143.170 .55 \mathrm{~nm}$, with a polydispersity index of 0.2290 .02 . Because the particle size was still in the region of $100-400 \mathrm{~nm}, \mathrm{~F} 3$ was chosen as the best condition. The particles will be able to pass through the Langerhans islets in the pancreas up to 69 percent of the follicular depth $(2000-4000 \mathrm{~m})$ at this size. A low polydispersion index value, on the other hand, suggests that liposomes have superior particle size homogeneity. ${ }^{16}$ According to previous study, increasing the surfactant concentration in a liposome formulation can increase particle size.This is due to the increasing number of surfactants that combine to form vesicles, causing the liposome particle size to increase. ${ }^{17}$

The significant value of homogeneity based on the difference in particle size of the liposomes of the ethanol extract of tekelan leaves was $\mathrm{p}>0.05$ using the One Way ANOVA approach (0.069). The liposome formulation is homogeneous, as evidenced by this. A significant value of $p>0.05(0.068)$ was found in the One Way ANOVA test. This demonstrates that there is no discernible change in particle size across the formulations.

The statistical observation of the One Way ANOVA approach obtained a significant value of p0.05 when examined based on the difference in sonication time (0.045). It is claimed that the modulation of sonication time in the liposome formulation of ethanol extract of tekelan leaves 
Table 5: Particle size observation results.

\begin{tabular}{|c|c|c|c|c|c|c|c|c|c|}
\hline \multirow{3}{*}{ Formula } & \multicolumn{9}{|c|}{ Sonication Time } \\
\hline & \multicolumn{3}{|c|}{10 minutes } & \multicolumn{3}{|c|}{20 minutes } & \multicolumn{3}{|c|}{30 minutes } \\
\hline & $\begin{array}{l}\text { Particle Size } \\
(\mathrm{nm} \pm \mathrm{SD})\end{array}$ & $\mathrm{Pl} \pm \mathrm{SD}$ & $\begin{array}{l}\text { Zeta Potential } \\
\quad(m V \pm S D)\end{array}$ & $\begin{array}{l}\text { Particle Size } \\
(\mathrm{nm} \pm \mathrm{SD})\end{array}$ & $\mathrm{PI} \pm \mathrm{SD}$ & $\begin{array}{l}\text { Zeta Potential } \\
(m V \pm S D)\end{array}$ & $\begin{array}{l}\text { Particle Size } \\
(\mathrm{nm} \pm \mathrm{SD})\end{array}$ & $\mathrm{PI} \pm \mathrm{SD}$ & $\begin{array}{l}\text { Zeta Potential } \\
\quad(\mathrm{mV} \pm \mathrm{SD})\end{array}$ \\
\hline I & $385.5 \pm 1.1$ & $0.419 \pm 0.058$ & $-62.7 \pm 0.17$ & $313.6 \pm 1.3$ & $0.345 \pm 0.04$ & $-35.2 \pm 0.9$ & $293.6 \pm 1.6$ & $0.307 \pm 0.03$ & $-42.9 \pm 0.6$ \\
\hline II & $343.6 \pm 1.6$ & $0.392 \pm 0.05$ & $-55.4 \pm 1,1$ & $275.7 \pm 1.2$ & $0.260 \pm 0.04$ & $-34.67 \pm 0.64$ & $201.90 \pm 1.54$ & $0.275 \pm 0.06$ & $-45.37 \pm 0.85$ \\
\hline III & $357,4 \pm 0.9$ & $0.377 \pm 0.05$ & $-64.23 \pm 1.0$ & $267.07 \pm 1.6$ & $0.320 \pm 0.01$ & $-35.93 \pm 0.64$ & $143.17 \pm 0.55$ & $0.229 \pm 0.02$ & $-42.2 \pm 1.0$ \\
\hline
\end{tabular}

Table 6: Observation results of liposomal organoleptic ethanol extract of tekelan leaves at room temperature storage $\left(25 \pm 0.5^{\circ} \mathrm{C}\right)$ for 12 weeks.

\begin{tabular}{llll}
\hline Formula & Inspection & Condition & After Observation \\
\cline { 3 - 4 } F1 & Smell & Before Observation & No Smell \\
& Color & No smell & Deep green \\
& Consistency & Deep green & two layers are formed \\
F2 & Smell & Thick & No smell \\
& Color & No smell & Deep green \\
F3 & Consistency & Deep green & Two layers are formed \\
& Smell & Thick & No smell \\
& Color & No smell & Deep green \\
& Consistency & Deep green & Two layers are formed
\end{tabular}

Table 7: Observation results of liposomal organoleptic ethanol extract of tekelan leaves $(C$. odorata $\mathrm{L}$.$) at low temperature storage \left(4 \pm 0.5^{\circ} \mathrm{C}\right)$.

$\begin{array}{llll}\text { Formula } & \text { Inspection } & \text { Condition } & \text { After } \\ \text { F1 } & \text { Smell } & \text { Before } & \text { No smell } \\ & \text { Color } & \text { No smell } & \text { Deep green } \\ \text { F2 } & \text { Consistency } & \text { Deep green } & \text { Thick } \\ & \text { Smell } & \text { No smell } & \text { Deep green } \\ & \text { Color } & \text { No smell } & \text { Thick } \\ \text { F3 } & \text { Consistency } & \text { Deep green } & \text { No smell } \\ & \text { Smell } & \text { Thick } & \text { Deep green } \\ & \text { Color } & \text { No smell } & \text { Deep green }\end{array}$

Table 8: Results of ethanol extract of tekelan leaves liposome adsorption efficiency.

\begin{tabular}{|c|c|c|c|c|}
\hline Formula & Replication & Absorbance & \%EE & Average $\pm S D$ \\
\hline & 1 & 0.0044 & 97.92 & \multirow{3}{*}{$97.52 \pm 1.51$} \\
\hline \multirow[t]{2}{*}{1} & 2 & 0.0075 & 95.85 & \\
\hline & 3 & 0.0031 & 98.79 & \\
\hline \multirow[t]{3}{*}{2} & 1 & 0.0033 & 98.66 & \multirow{3}{*}{$98.55 \pm 1.24$} \\
\hline & 2 & 0.0017 & 99.73 & \\
\hline & 3 & 0.0054 & 97.25 & \\
\hline \multirow[t]{3}{*}{3} & 1 & 0.0019 & 99.59 & \multirow{3}{*}{$99.66 \pm 0.18$} \\
\hline & 2 & 0.0015 & 99.86 & \\
\hline & 3 & 0.002 & 99.53 & \\
\hline
\end{tabular}

is significant. When this is combined with the Tukey HSD test, two distinct groups emerge. At the 20th and 30th minutes, both groups had a significance value of $\mathrm{p}>0.05$ (0.693). Meanwhile, a significant value of $\mathrm{p}>0.05(0.199)$ was achieved at the 10 and 30 minutes. This demonstrates that based on differences in sonication duration between the 20 and 30 minutes, as well as between the 10 and 15 minutes.

\section{Determination of physical stability test}

The organoleptic data of ethanol extract of tekelan leaves liposomes was evaluated during the course of 12 weeks of storage, with observations every week. Changes in color, odor, shape, particle size, and phase separation were found in liposomes maintained at room temperature. Table 6 shows the findings of the liposome preparations examination.

\section{Storage stability results at low temperatures $\left(4 \pm 0.5^{\circ} \mathrm{C}\right)$}

Evaluation of organoleptic observations of the preparation was carried out during 12 weeks of storage with observations every 1 week, the liposome preparation of ethanol extract of tekelan leaves (C. odorata L.) was stored at low temperature $\left(4 \pm 0.5^{\circ} \mathrm{C}\right)$ and observed changes in color, odor, shape, particle size. and phase separation. The results of the evaluation of the stability of the liposome preparations can be seen in Table 7.

Table 7 shows the stable ethanol extract of tekelan leaves liposomes during storage. color, odor and shape did not change from the beginning of observation until storage for 12 weeks. Phase separation is also not formed. The lower the storage temperature, the higher the 


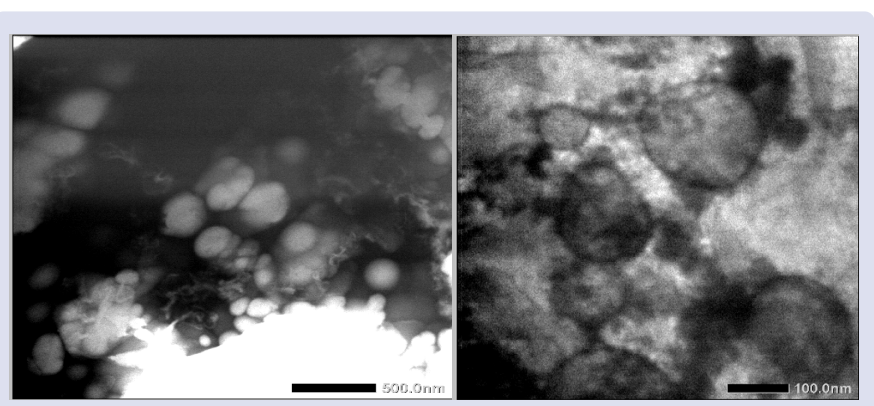

Figure 1: TEM results at 10,000 times magnification of liposome ethanol extract of tekelan leaves (C. odorata L.) formulation-3 with sonication time 30 minutes (a) before purification, (b) after purification.

stability of the drug. This is related to the decomposition of active substances and complementary substances in the drug will be smaller so that the resulting levels will be even greater. ${ }^{18}$

\section{Liposome morphology}

The liposome morphology of the ethanol extract of tekelan leaves (C. odorata L.) was observed by Transmission Electron Microscopy (TEM). The selection of the TEM instrument was made because this instrument is best used to show the morphology of nanometer-scale liquid preparations. ${ }^{19}$ The working principle of TEM is that electrons are fired and passed through the specimen object by focusing the electrons by the condenser lens. Then the electrons will hit the fluorescent screen, where the screen will emit light when exposed to electrons..$^{20}$ The results of TEM observations of liposomes from tekelan leaf extract (C. odorata L.) can be seen in Figure 1 above.

Before and after purification, TEM (Transmission Electron Microscope) images of liposomes from tekelan leaf extract revealed a somewhat rounded form with various particle sizes. The TEM size of the liposomes of tekelan leaf extract before purification was $500 \mathrm{~nm}$, however after purification, the TEM size was reduced to $100 \mathrm{~nm}$. The amount of lipid, the solvent, and the surfactant used to generate the vesicle all had an impact on its diameter, according to the researchers. ${ }^{21}$ The particle size after purification was less than before purification, according to the researchers. ${ }^{18}$

\section{Adsorption efficiency}

The efficacy of vesicle entrapment was assessed using an ultracentrifugation technique to separate the free drug from the drug absorbing vesicle. To separate the medicine that is not adsorbed from the lipid vesicles that have formed, they were centrifuged for 30 minutes at $3000 \mathrm{rpm}$ and $4^{\circ} \mathrm{C}$. The quercetin molecule in the centrifuged supernatant was not adsorbed, and its absorbance could be determined using UV-VIS spectrophotometry. Table 7 shows the results of the adsorption efficiency test.

The amount of extract adsorbed in the liposome crosslinker is expressed as a percentage of entrapment efficiency. Because its value can indicate the ability of the crosslinker to transfer the active component to the therapeutic target, adsorption efficiency is mostly used in drug delivery systems. The solubility of the medication in the matrix or polymer, as well as the amount of polymer utilized, determine the entrapment efficiency of a particle. The medicine is strongly adsorbed in the polymer/matrix since the ethanol extract of Duan Tekelan is freely soluble in it. ${ }^{22}$

\section{CONCLUSION}

The thin layer hydration method can be used to synthesize ethanol extract of tekelan leaves into liposome formulations. Liposomes made from tekelan leaf ethanol extract are odorless, dark green in color, and thick in consistency and are stable when stored at low temperatures $\left(40 \pm 5^{\circ} \mathrm{C}\right)$. It is, however, unstable at room temperature $\left(25 \pm 5^{\circ} \mathrm{C}\right)$, with an organoleptic condition devoid of odor, a dark green color, and a consistency consisting of two layers: a clear layer and a cloudy layer.

\section{ACKNOWLEDGEMENT}

The researcher would like to express his gratitude to everyone who took part in this study. Specifically for the Islamic University of Indonesia's Nano Pharmacist Research Center Laboratory, Gadjah Mada University's Chemistry Laboratory, and the Universitas Sumatera Utara, Faculty of Pharmacy's Phytochemical Laboratory.

\section{REFERENCES}

1. Akinmoladun AC, Ibukun EO, Dan-Ologe IA. Phytochemical constituents and antioxidant properties of extracts from the leaves of Chromolaena odorata. Scientific research and essays. 2007;2(6):191-4.

2. Ezenyi IC, Salawu OA, Kulkarni R, Emeje M. Antiplasmodial activity-aided isolation and identification of quercetin-4'-methyl ether in Chromolaena odorata leaf fraction with high activity against chloroquine-resistant Plasmodium falciparum. Parasitology Research. 2014;113(12):4415-22.

3. Madaan K, Lather V, Pandita D. Evaluation of polyamidoamine dendrimers as potential carriers for quercetin, a versatile flavonoid. Drug delivery. 2016;23(1):254-62.

4. Large DE, Abdelmessih RG, Fink E, Auguste DT. Liposome composition in drug delivery design, synthesis, characterization, and clinical application. Advanced Drug Delivery Reviews. $2021 ; 113851$.

5. Laouini A, Jaafar-Maalej C, Limayem-Blouza I, Sfar S, Charcosset C Fessi H. Preparation, characterization and applications of liposomes: state of the art. Journal of colloid Science and Biotechnology. 2012;1(2):147-68.

6. Mufamadi MS, Pillay V, Choonara YE, Du Toit LC, Modi G, Naidoo D, et al. A review on composite liposomal technologies for specialized drug delivery. Journal of drug delivery. 2011.

7. Weiner N, Martin F, Riaz M. Liposomes as a drug delivery system. Drug Development and Industrial Pharmacy. 1989;15(10):1523-54.

8. Marianne M, Lestari D, Sukandar EY, Kurniati NF, Nasution R. Antidiabetic Activity of Leaves Ethanol Extract Chromolaena odorata (L.) RM King on Induced Male Mice with Alloxan Monohydrate. Journal natural. 2014;14(1).

9. Hapsari M, Purwanti T, Rosita N. Penetrasi natrium diklofenaksistemniosom span 20-kolesteroldalam basis gel hpmc 4000. Pharm Sci. 2012;1(2):44-57.

10. Lee JM, Park H, Oh KT, Lee ES. pH-Responsive hyaluronated liposomes for docetaxel delivery. International journal of pharmaceutics. 2018;547(1-2):377-84.

11. Smith MC, Crist RM, Clogston JD, McNeil SE. Zeta potential: a case study of cationic, anionic, and neutral liposomes. Analytical and bioanalytical chemistry. 2017;409(24):5779-87.

12. Noviza D, Lucida H, Suharti N, Pinto PB. Formulation of Liposome using Sappan wood (Caesalpinia Sappan L.) Ethyl acetate Fraction as an activate compound. Oriental Journal of Chemistry. 2018;34(3):1611

13. Sopyan I, Gozali D. A Review: A Novel of Efforts to Enhance Liposome Stability as Drug Delivery Approach. Systematic Reviews in Pharmacy. 2020;11(6).

14. Ministry of Health of The Republic of Indonesia, 1995, Materia Medika Indonesia, Volume VI. Sixth Print, Directorate General of Drug and Food Control, Jakarta. pp.321-325. 
15. Shao XR, Wei XQ, Zhang S, Fu N, Lin YF, Cai XX, et al. Effects of micro-environmental $\mathrm{pH}$ of liposome on chemical stability of loaded drug. Nanoscale research letters. 2017;12(1):1-8.

16. Lin L, Zhu Y, Thangaraj B, Abdel-Samie MA, Cui H. Improving the stability of thyme essential oil solid liposome by using $\beta$-cyclodextrin as a cryoprotectant. Carbohydrate polymers. 2018;188:243-51.

17. Liu RR, Cannon JB, Paspal SY. Liposomes in solubilization. InWaterInsoluble Drug Formulation 2018;pp.405-449.

18. Scicluna MC, Vella-Zarb L. Evolution of nanocarrier drug-delivery systems and recent advancements in covalent organic frameworkdrug systems. ACS Applied Nano Materials. 2020;3(4):3097-115.

19. Ramli SF, Abdul Aziz H, Mohd Omar F, Yusoff MS, Halim H, Kamaruddin MA, Ariffin KS. Removal of colour and suspended solids from landfill leachate using Tin tetrachloride ( $\mathrm{SnCl} 4)$ : The effects of $\mathrm{pH}$, zeta potential, and particle sizes. International Journa of Environmental Analytical Chemistry. 2021;s-6.

20. Han SM, Na YG, Lee HS, Son GH, Jeon SH, Bang KH, et al Improvement of cellular uptake of hydrophilic molecule, calcein, formulated by liposome. Journal of Pharmaceutical Investigation. 2018;48(5):595-601.

21. Matsui F, Matsuda H. Projection-type electron spectroscopy collimator analyzer for charged particles and x-ray detections. Review of Scientific Instruments. 2021;92(7):073301.

22. Umbarkar MG. Niosome as a Novel Pharmaceutical Drug Delivery: A Brief Review Highlighting Formulation, Types, Composition and Application. Indian J. Pharm. Educ. Res. 2021s;55:s11-28.

\section{GRAPHICAL ABSTRACT}

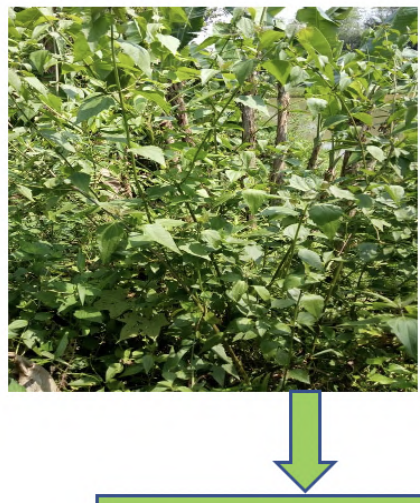

\section{extraction}

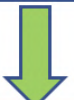

\section{Liposome formulation} And Evaluation

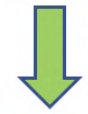

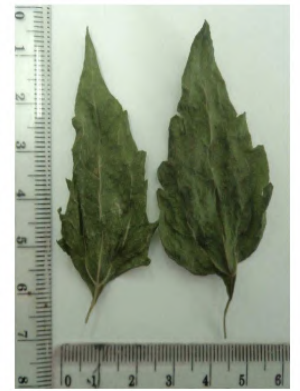

Phytochemical Screening

\begin{tabular}{|l|l|l|}
\hline Compound & Powder & Extract \\
\hline Alkaloids & + & + \\
\hline Flavonoids & + & + \\
\hline Tanins & + & + \\
\hline Saponins & + & + \\
\hline Steroids/Trit & + & + \\
erpenoids & + & + \\
\hline Glycoside & + & + \\
\hline
\end{tabular}

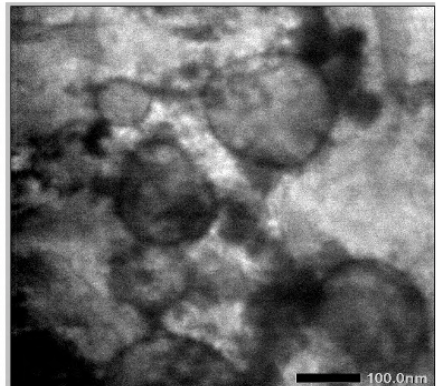




\section{ABOUT AUTHORS}

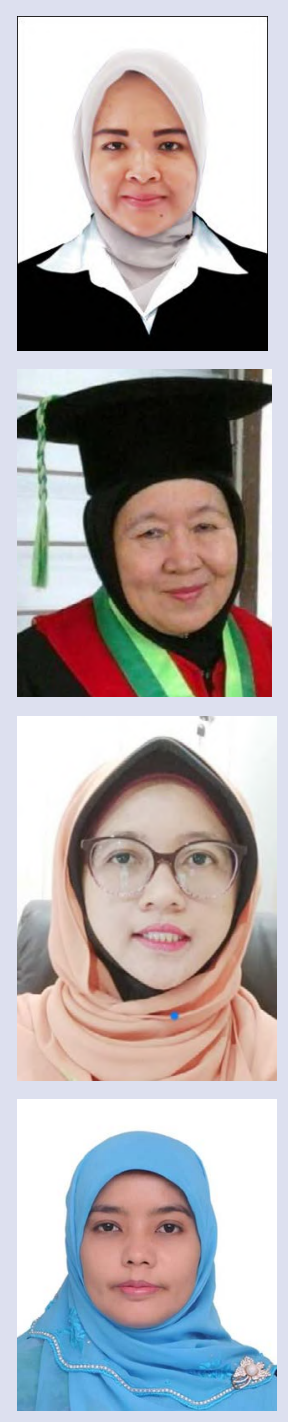

Sofia rahmi is Doctoral Student at the Faculty of Pharmacy, Universitas Sumatera Utara. She completed her undergraduate and Faculty of Pharmacy, Universitas Sumatera Utara, and she is working as lecture at Health Institute of Deli Husada Deli Tua.

Rosidah is a Professor at Faculty of Pharmacy, Universitas Sumatera Utara, Medan, Indonesia. Her research interest is in pharmacological activity of medicinal plant.

Tri Widyawatiis a Lecturer at Medical Faculty, Universitas Sumatera Utara, Medan, Indonesia since 2003. Her PhD was graduated from Pharmaceutical Sciences University Sains Malaysia 2016. Currently, besides being a lecturer she is also the head of the Pharmacology and Therapeutic department in her institution. Her research interest is in pharmacological activity of medicinal plant. Currently she is studying the potential effect of active compound as antidiabetic and herbs combination as an immunomodulator.

Sumaiyah is a Lecturer at Faculty of Pharmacy, Universitas Sumatera Utara (USU), Medan, Indonesia. Her PhD was graduated from Faculty of Pharmacy, Universitas Sumatera Utara in 2014. Her research interest is in Pharmaceutics and Pharmaceutical Technology.

Cite this article: Rahmi S, Rosidah, WidyawatiT, Sumaiyah. Liposome Preparation of Tekelan Leaf (Chromolaenaodorata L.) Extract: Manufacturing and Evaluation. Pharmacogn J. 2022;14(1): 56-62. 